\title{
Generation of an activation map for decommissioning planning of the Berlin Experimental Reactor-II
}

\author{
Janis Lapins ${ }^{1, a}$, Nicole Guilliard ${ }^{1}$ and Wolfgang Bernnat ${ }^{1}$ \\ ${ }^{1}$ Institute of Nuclear Technology and Energy Systems (IKE), University of Stuttgart, 70569 Stuttgart, Germany
}

\begin{abstract}
The BER-II is an experimental facility with 10 MW that was operated since 1974. Its planned operation will end in 2019. To support the decommissioning planning, a map with the overall distribution of relevant radionuclides has to be created according to the state of the art. In this paper, a procedure to create these 3-d maps using a combination of MCNP and deterministic methods is presented. With this approach, an activation analysis is performed for the whole reactor geometry including the most remote parts of the concrete shielding.
\end{abstract}

\section{Introduction}

The BER-II is a light water cooled pool type $10 \mathrm{MW}$ reactor with UAl-plate fuel elements of MTR-type [1,2] The core consists of 30 fuel elements, in a $6 \times 7$ grid plate. Some positons are filled with beryllium reflectors. There are 6 control rods and a total height of $60 \mathrm{~cm}$. Also there is a permanent beryllium reflector around the core, and one in-core irradiation channel, see Figure 1. The core is submerged in a pool of 3.5 metres diameter and a depth of 11 metres. Next to the reactor pool, there is a second pool for discharged fuel elements. The pools are surrounded by massive concrete structures; barite concrete around the core pool, normal concrete for the other pool (Figures 2 and 3).

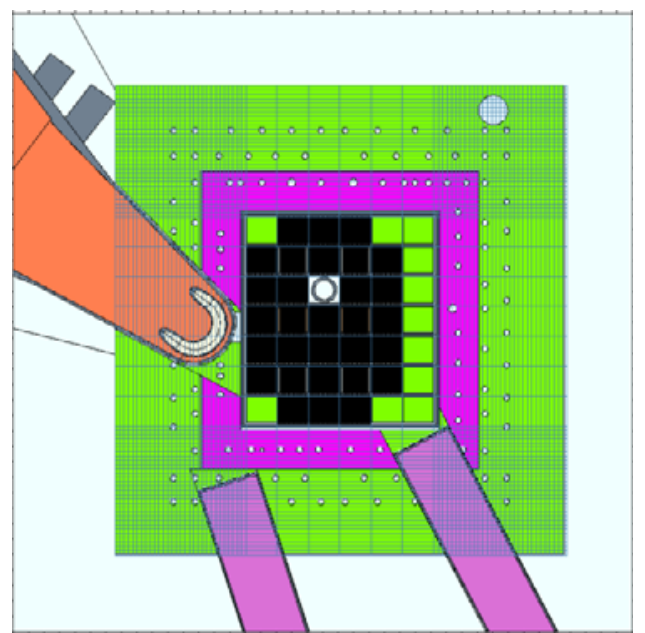

Figure 1: Horizontal cross section of the core with fuel elements (black), beryllium (green and magenta), ends of irradiation channels (light pink)

\footnotetext{
a Janis.lapins@ike.uni-stuttgart.de
}

The barite concrete structures are penetrated by multiple irradiation tubes to allow for neutron experiments. With its 10 tangential, diagonal and radial irradiation channels and one conical beam tube housing the cold neutron source, see Figure 4, a cylindrically symmetric approach cannot be applied and the reactor is fully modelled in 3 dimensions.

The reactor will operate until the end of 2019. The activation analysis comprises all load periods until the planned shutdown.

\section{Methods and models}

In order to have an accurate description of all the components with their real geometric complexity, MCNP6 [3] is used to create the geometry model. With MCNP6, all components can be input explicitly without discretisation. However, for MCNP6 it is rather time consuming, if not impossible, to calculate the neutron flux distribution for the most remote parts of the concrete. Given that, a different approach was applied. MCNP6 has an automatic geometry export option which can be used for the discrete ordinates transport code PARTISN [4]. Since PARTISN needs a discretisation, a mesh grid subdivision in $\mathrm{x}, \mathrm{y}, \mathrm{z}$-direction has to be provided within the MCNP6 input before applying the export option. When using the export function, the reactor geometry is subdivided into volumes according to the subdivision done by the user with up to 6 different materials from MCNP6 being mixed together with their respective volume fractions. For all different materials appropriate 
macroscopic cross sections (XS) have to be generated for PARTISN and subsequently used for determination of the neutron flux distribution. To create these XS, use is made of the SCALE6 package [5]. In this package the ENDF/B-VII.1 library [6] is available in 238 energy group structure and different $\sigma_{0}$-background cross sections to account for self-shielding effects in both fuel and structure materials. The self-shielding was treated with the BONAMI module of SCALE6 applying the Bondarenko method. The 238 group library was then used for radial 1-d spectrum calculations with ANISN [7] to get 238 group spectra for the different material regions of interest. The 1D- calculations were performed with the $\mathrm{S}_{\mathrm{N}}$ order 16 and the Legendre expansion $\mathrm{P}_{5}$ to account for anisotropic scattering. The cross sections for all different materials of the material specifications of the MCNP6 model and the PARTISN model were then condensed from 238 to 65 groups to limit the computational effort for the 3D-PARTISN calculations. With the spectrum weighted macroscopic 65 group XS, the neutron transport equation was solved for the whole reactor geometry with PARTISN. The solution is a detailed flux distribution in 65 groups for a fine mesh grid. The calculation was performed as eigenvalue problem. For the range of the core a flat burnup distribution was assumed and an average operational control-rod bank position to reach an effective multiplication factor near to one. A control with the MCNP6 model showed a good agreement with the multiplication factor calculated by PARTISN.

For the activation analysis, more data have to be available, e.g. the power history over the whole lifetime has to be accounted for; also the detailed compositions of all materials for which activation has to be determined. This comprises not only the main nuclides necessary to compute the neutron flux, but also the traces of manufacturing impurities such as uranium, cobalt, caesium, europium or gadolinium etc. The activation calculations itself were performed with the program FISPACT [8]. The FISPACT program package contains activation cross section for a large number of nuclides for the most important $(\mathrm{n}, \mathrm{X})$ reactions and corresponding decay data. The cross section libraries are available in different group structures. The group structures used here were 69 groups (WIMS structure) for PARTISN and 315 groups for MCNP6. All spectra with the 65 group structure of PARTISN were converted to the 69 group structure of the FISPACT library, the 292 group spectra of the MCNP results to the 315 group structure. The weighted activation XS for the calculation of the nuclide build-up and decay finally were generated by collapsing the 69 or 315 group XS via the converted spectra.

This whole procedure is depicted in Figure 5. On the left side of this figure, there is also the MCNP6 transport calculation step included that is especially performed if certain details have to be calculated more accurately without discretization, e.g. the activity of certain screw nuts. To get a flux distribution around the beam tubes based on continues energy cross sections, special MCNP6 transport calculations were performed for fine mesh grids (mesh tallies in environment of beam tubes). For these calculations, weight windows were generated derived from adjoint fluxes calculated with PARTISN.

\subsection{The BER-II geometry model in MCNP6}

The geometry of the BER-II was modelled with MCNP6. From a previous project that concerned the optimisation of the geometry of the cold neutron source container, the model of the core up to the aluminium liner was already available. In this work, the components surrounding the reactor pool were complemented. This includes the spent fuel pool, the concrete shielding, and the irradiation tubes with their respective penetrations within the concrete to coincide with the irradiation tubes within the reactor pool. The model comprises 17 different materials: the fuel elements, $\mathrm{AlMg}_{3}$, water, beryllium, helium, $\mathrm{CO}_{2}$, air, stainless steel, steel, grey cast iron, boron carbide, bismuth pellets, lead shot, normal concrete, magnetite concrete, barite concrete, and concrete bricks with a steel coating. However, the barite concrete also contains steel reinforcements which are denser in the region close to the reactor pool and the region next to the reactor hall (see Figure 6 , three subdivision of the barite concrete). All, materials are assumed at $300 \mathrm{~K}$, except the hydrogen chamber in the conical irradiation tube which is at $25 \mathrm{~K}$.

Using the export option from MCNP6 to PARTISN the geometry is discretised according to the user-provided subdivisions. The material specification in every mesh volume of the grid is a homogeneous mixture of materials sharing the mesh according to its fraction. While the mesh grid is finer in the core region (approx. $3.5 \mathrm{~cm}$ ), the mesh size increases towards the periphery $(5+\mathrm{cm})$. The coarsest mesh size is $11 \mathrm{~cm}$. The overall number of computational cells for the whole geometry in PARTISN is $2,790,000(155 \times 120 \times 158)$

Material specifications for the activation calculations are provided by the Helmholtz-Zentrum Berlin (HZB). However, for some components there are only unprecise material specifications, e.g. Co $<10 \mathrm{ppm}$ which are not measured afterwards. Since cobalt is not an alloy element, the respective content is estimated according to either values from literature or from other reactor activation analysis. Here, measured values for impurities of uranium, caesium, gadolinium, cobalt, and europium content could be used for this analysis. 


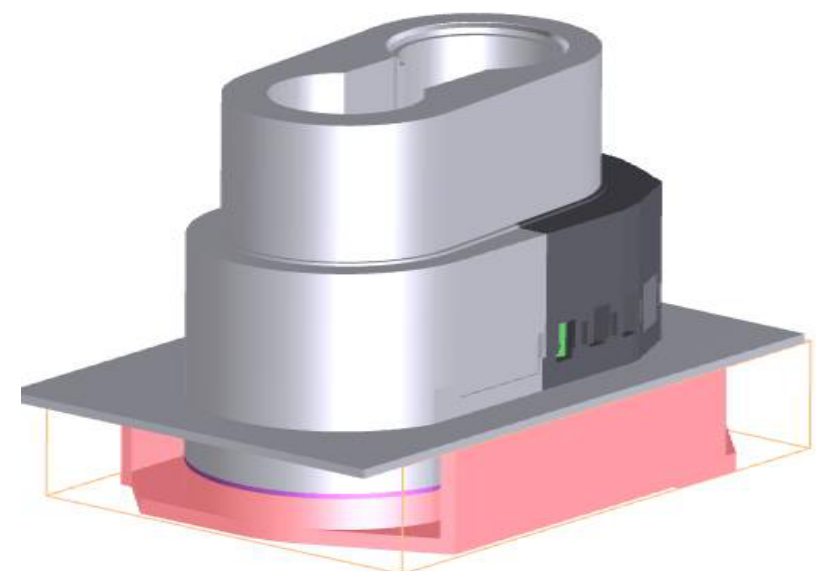

Figure 2: 3D-Model of the BER-II reactor /1 /

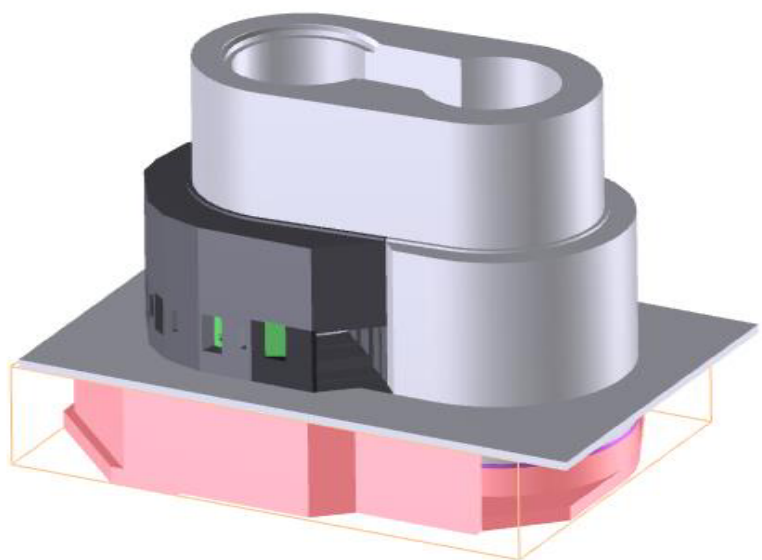

Figure 3: 3D-Model of the BER-II reactor /1 /

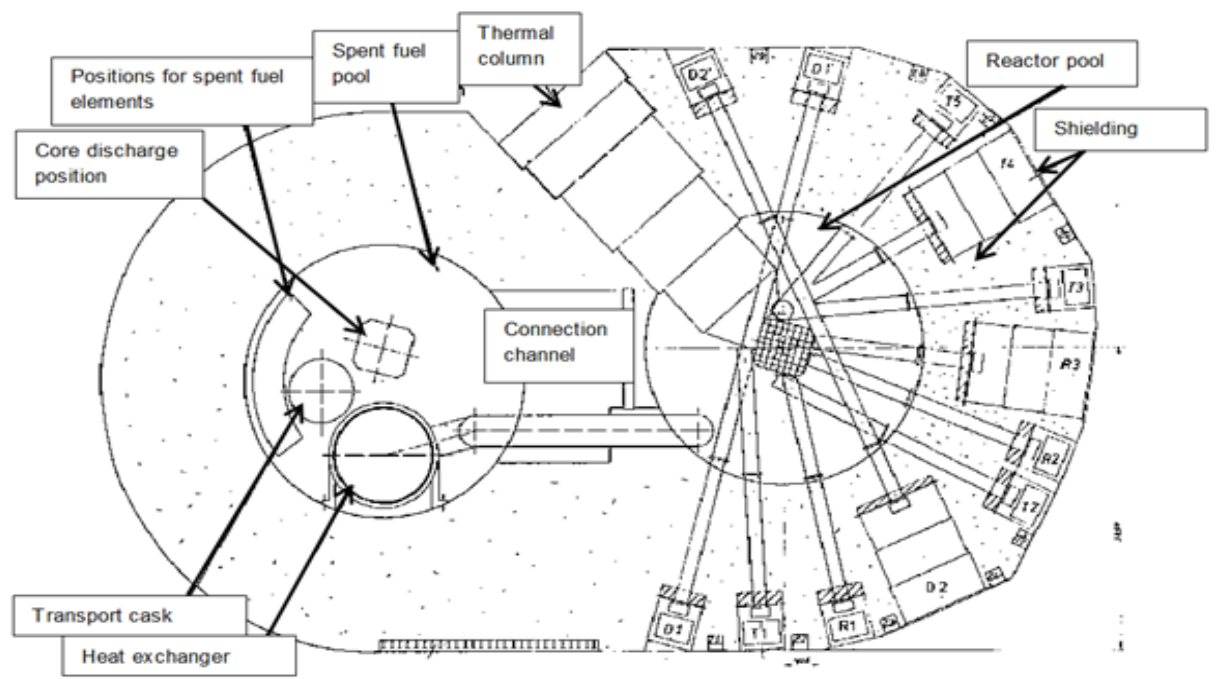

Figure 4: Horizontal cross section of the BER-II with irradiation channels before retrofitting in 1985 - 91, there is a graphite thermal column instead of a conical irradiation tube housing a cold neutron source $/ 1 /$.

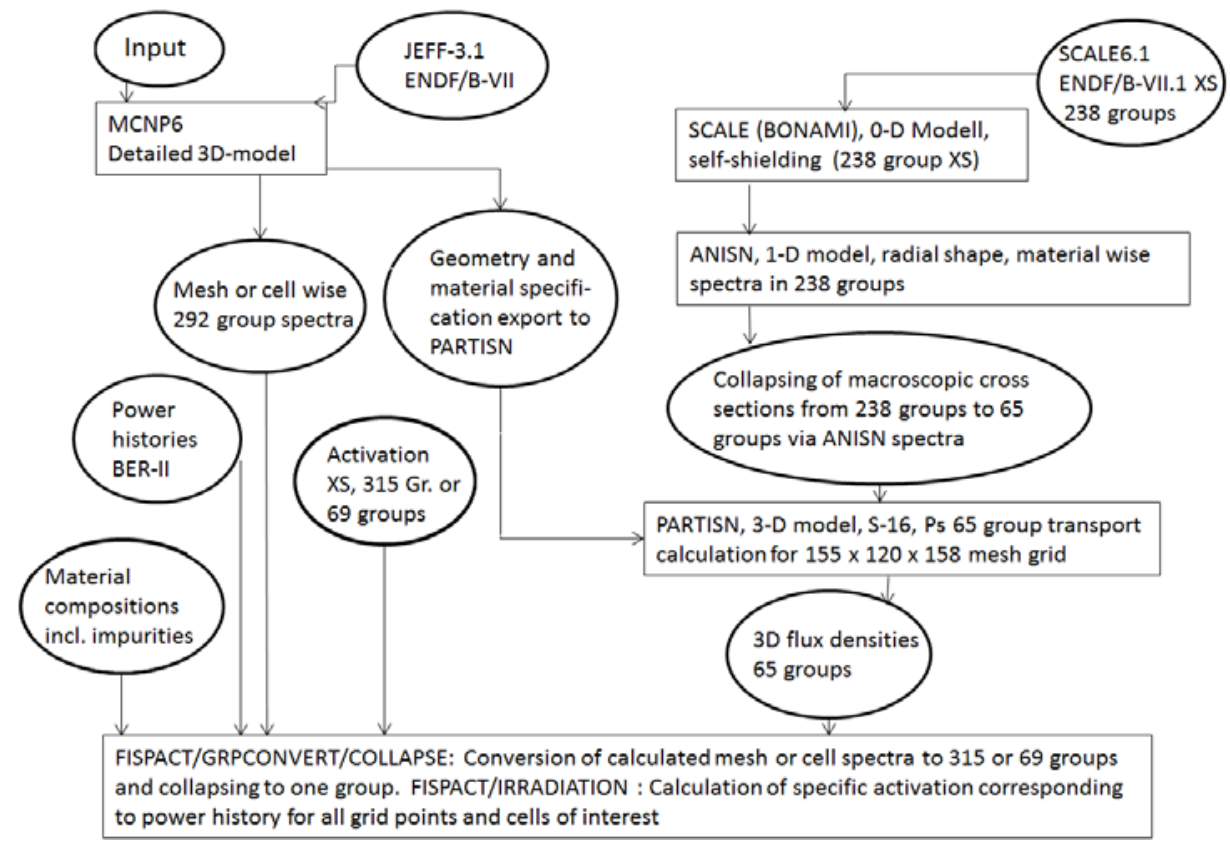

Figure 5: Flowchart for transport calculations with MCNP and PARTISN and activity calculations with FISPACT. 

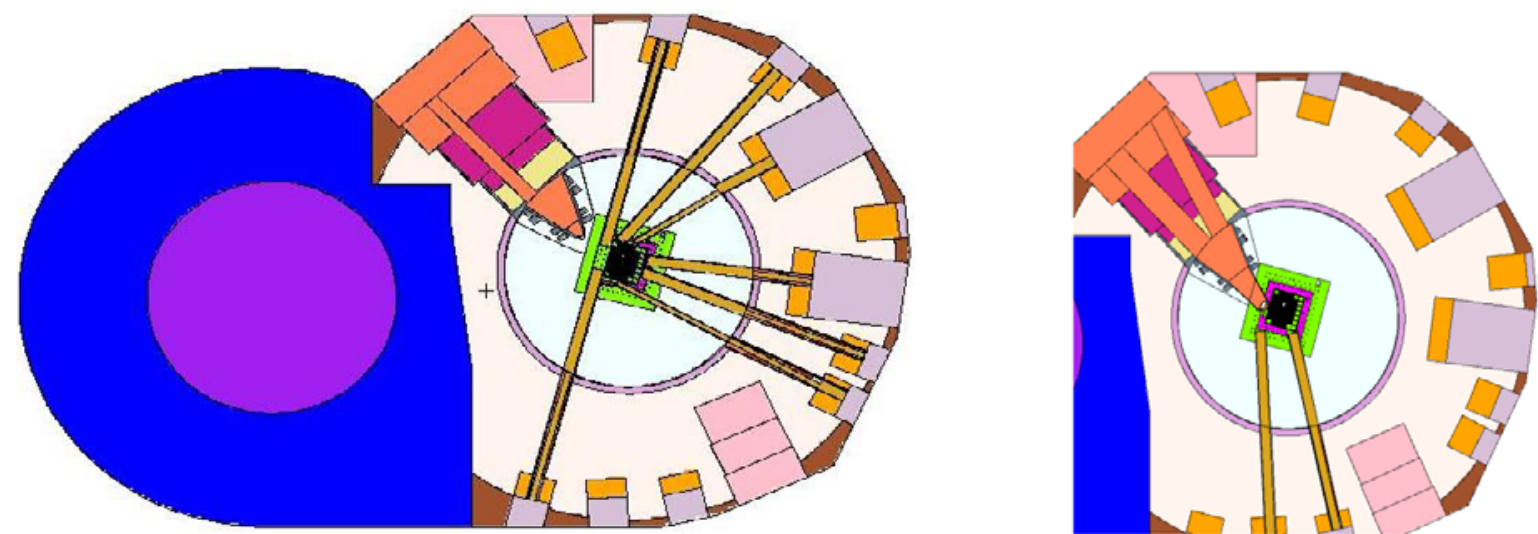

Figure 6: Horizontal sections at the plane with 7 out of 9 beam tubes (left) and the cold neutron source within the conical beam tube and two beam tubes (right). The barite concrete structure is subdivided into three parts according to their steel reinforcement content.

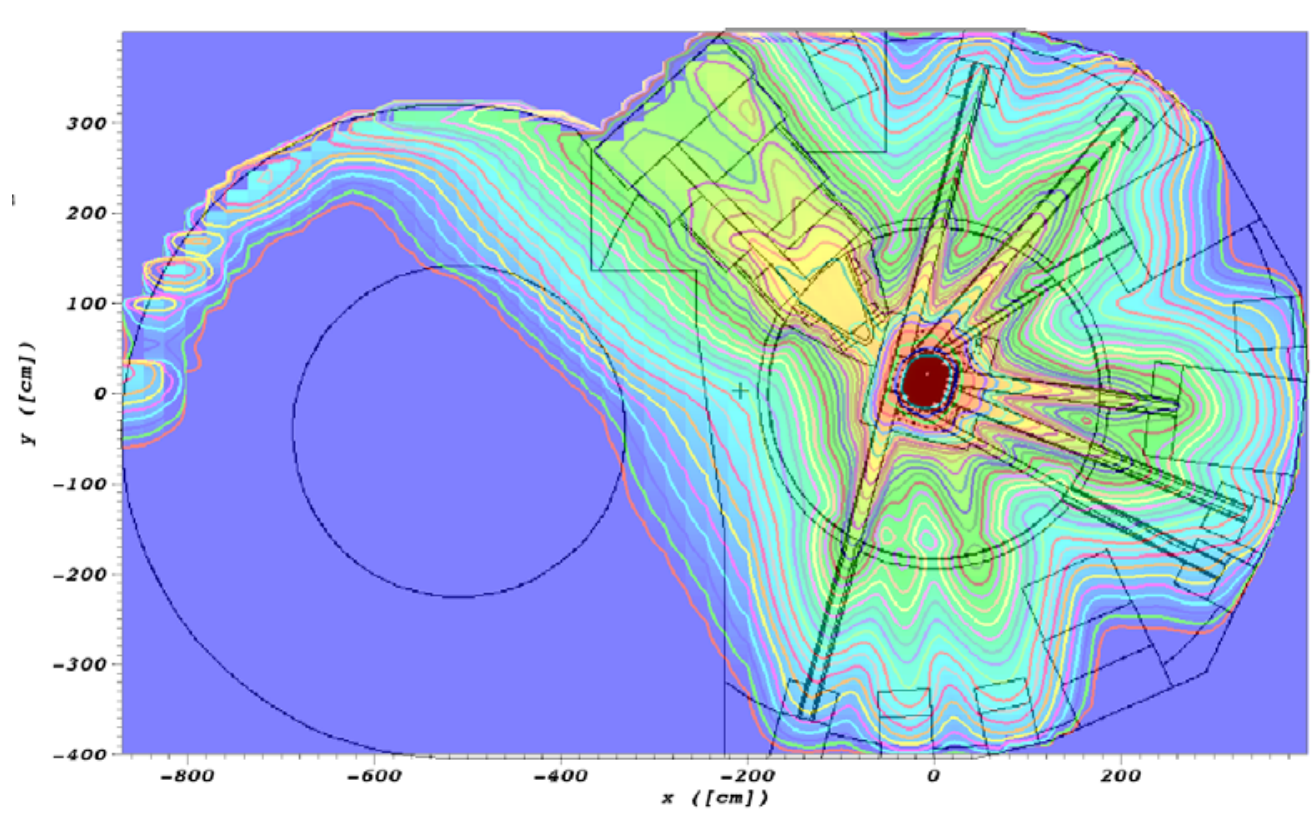

Figure 7: Fast neutron flux distribution in the x,y-plane with 7 irradiation tubes.

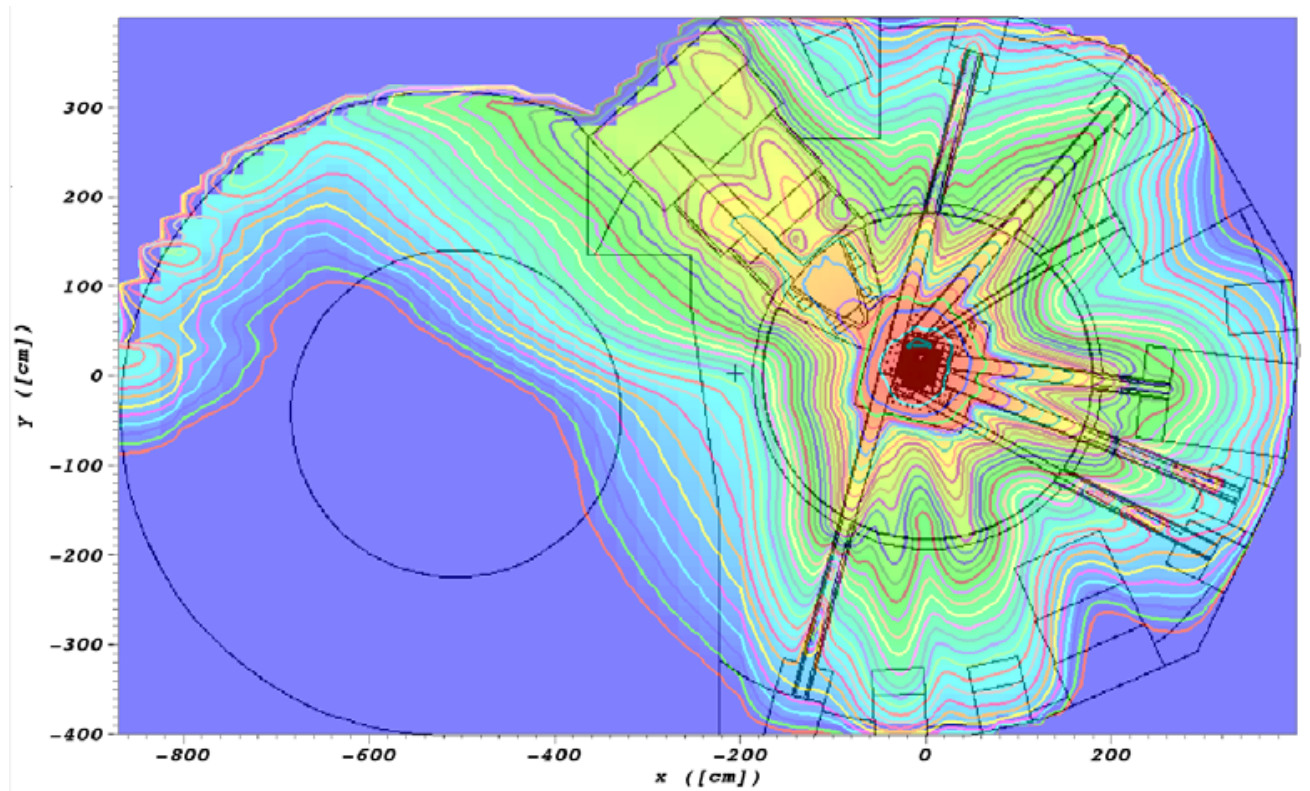

Figure 8: Thermal neutron flux in the $\mathrm{x}, \mathrm{y}$-plane of 7 irradiation tubes

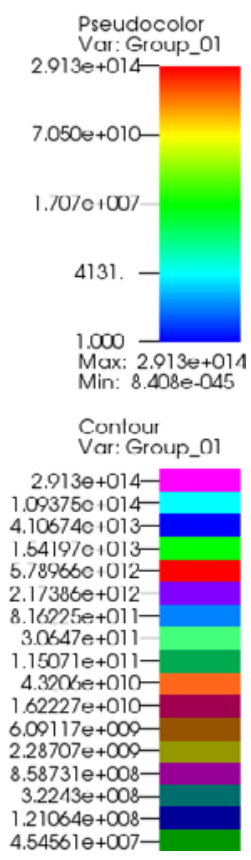

Pseudocolor $1.735 c+014$

$4.781 \theta+010$

$1.317 \theta+007$

3629.

1.0001 Min: 5.8850044

Contour

Var: Group_@2

$1.735 e+014$ $6.61449 e+013$ $9.6137 e+012$ $3.66512 \theta+012$ $1.39728 \mathrm{e}+012$ $5.32699 \mathrm{e}+011$ $5.37699 \mathrm{e}+011$
$2.03086 \mathrm{e}+011$ $7.742410+010$ $2.95171 e+010$ $1.1253 \mathrm{e}+010$ $4.2901 \theta+009$ $1.635550+009$ $6.23536 \mathrm{e}+008$ $2.37716 e+008$ $9.06266 \theta+007$ 


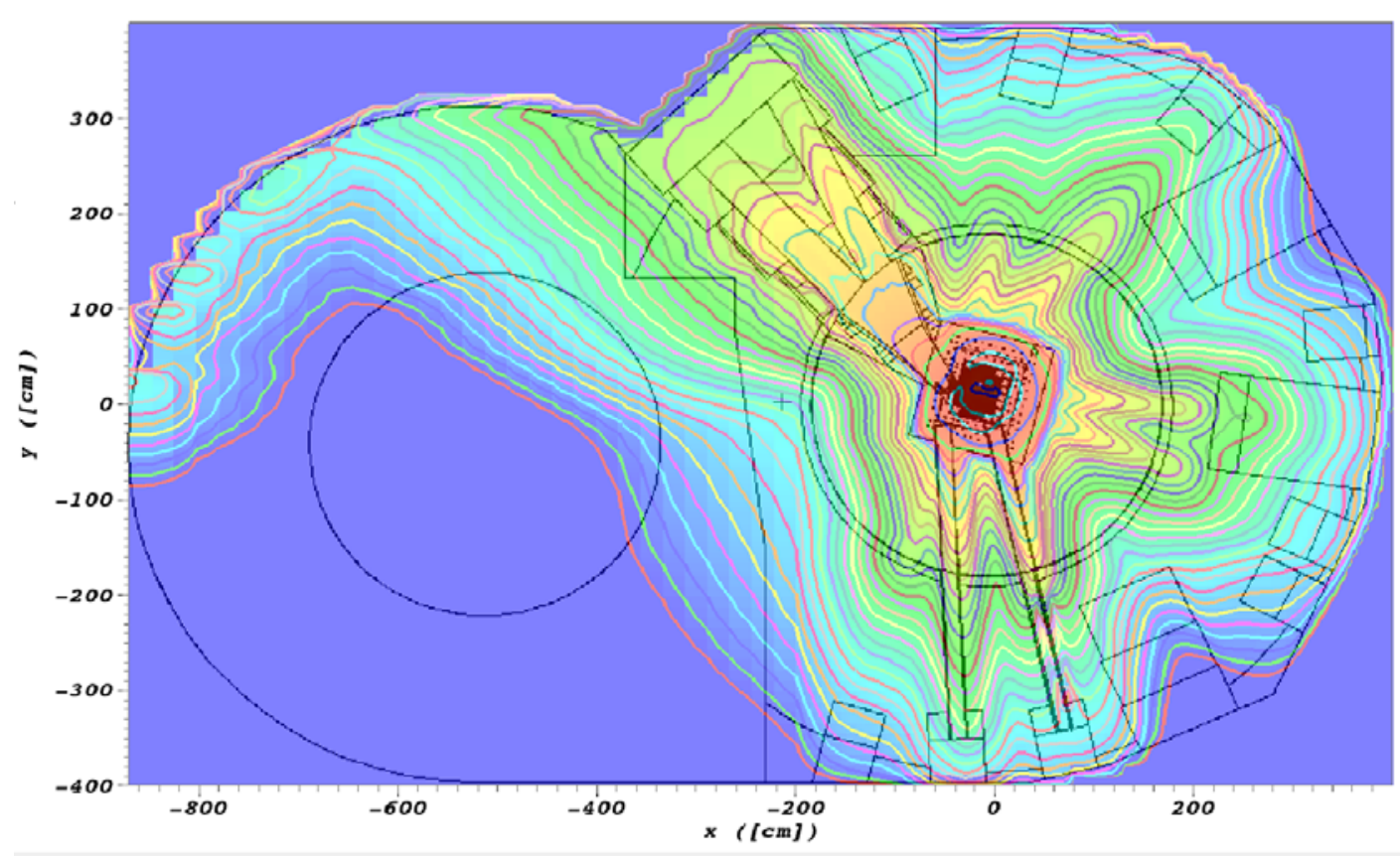

Figure 9: Fast neutron flux in the $x, y$-plane of 2 irradiation tubes and the conical tube of cold neutron source
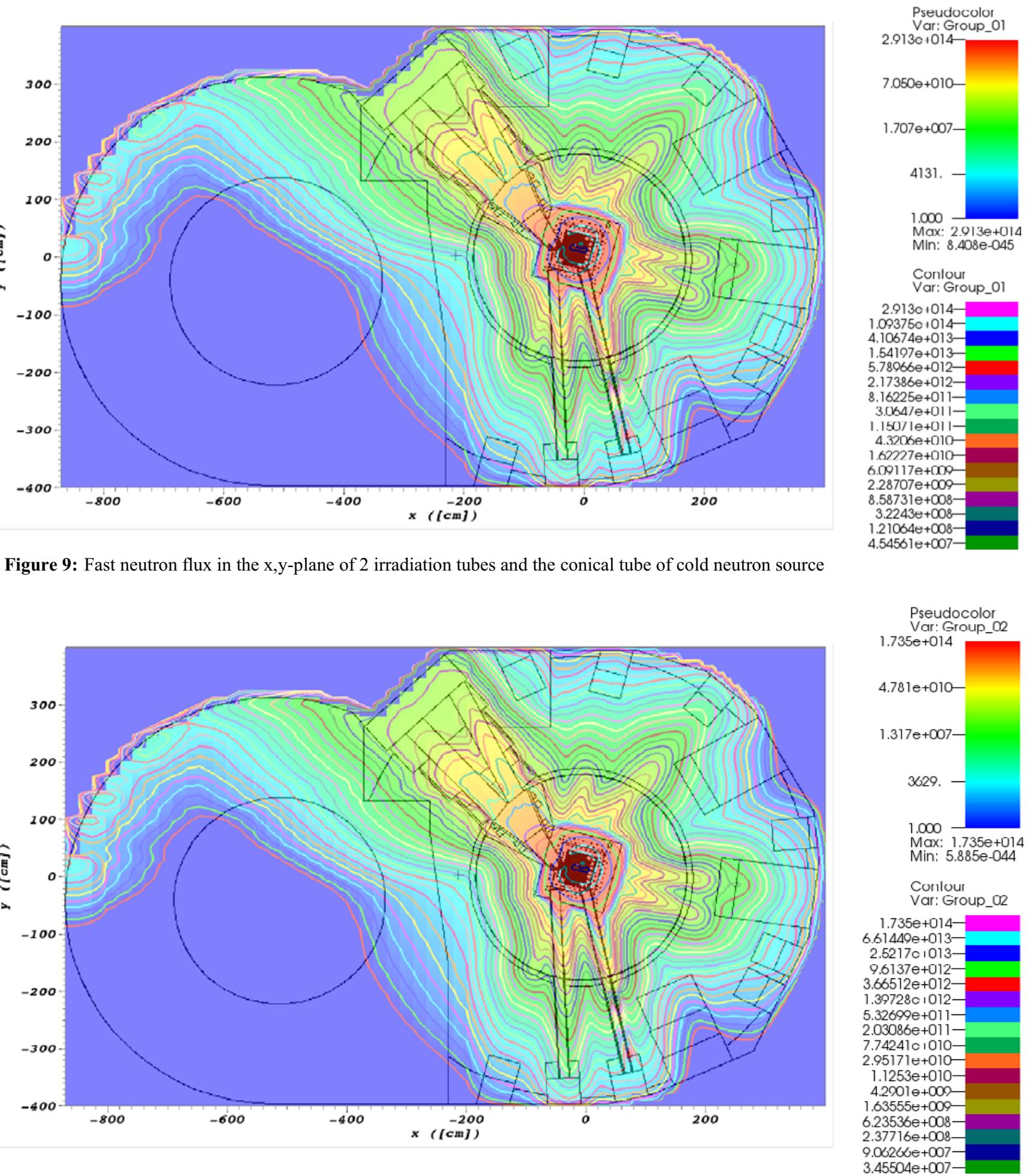

Figure 10: Thermal neutron flux in the $x, y$-plane of 2 irradiation tubes and the conical tube of cold neutron source

\section{Results of the Neutron Flux Calculation}

The neutron flux distribution of the BER-II calculated with PARTISN for the full geometry model is shown for two horizontal sections of major interest, i.e. the heights of the two different levels of the irradiation tubes. In one section there are the seven irradiation tubes, in the other section there are two irradiation tubes and the conical beam tube housing the cold neutron source. The corresponding fast and thermal fluxes are shown in Figures 7-10, respectively. The figures show that neutrons escape through the large conical beam tube containing the neutron guides and through the surrounding concrete structure and increase the fast and thermal flux density next to it and even at the leftmost (upper) side by travelling through the concrete structure of the pool for discharged fuel elements, 
Since the geometric structure of the conical beam tube housing the cold source and the neutron guides was very complicated, a separate flux density calculation for this region was made with a fine mesh-grid by MCNP6. The weight windows for this MCNP6 run were prepared by an adjoint PARTISN calculation. The thermal flux distribution for this region is shown in

Figure 11:
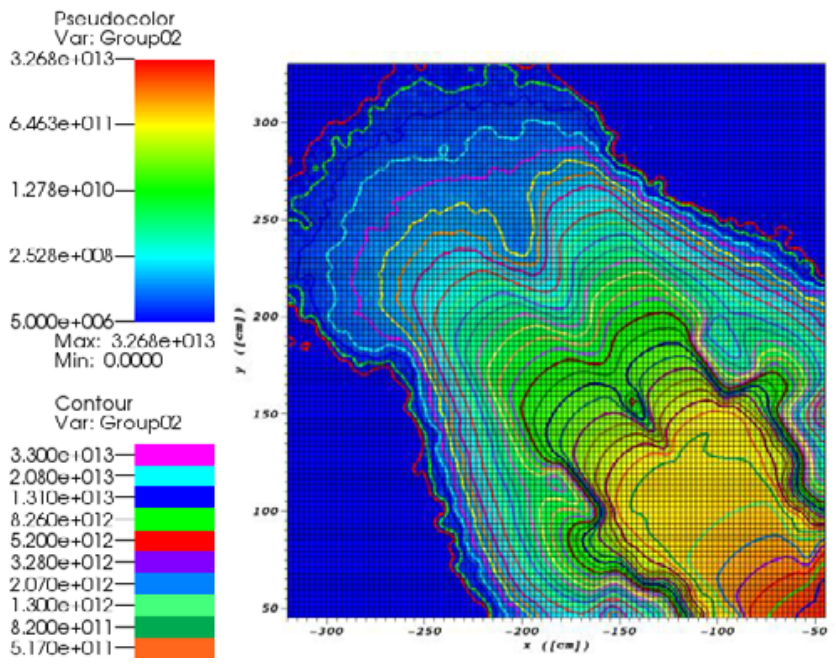

Figure 11: Thermal flux distribution in the conical beam tube and surrounding concrete

\section{Power Histories used for the activation calculations}

For the activation, it is important to know the neutron flux distribution throughout the whole operational lifetime. In this analysis, it is assumed that the neutron flux distribution throughout the whole operation time keeps the shape, but the amplitude is adjusted with respect to the increase in burn-up in a certain time interval. For the years 1974 - 1985, the increase of burn-up is only given for a whole year. Starting from 1991, the increase in burn-up is given in weeks. From there on, the power level is adjusted such that the power produced matches the burn-up increase. This is done for the $1991-2015$. For the years 2016 - 2019 there are only prognoses of the planned power production. As only the planning for the year 2016 is available, the years 2017 - 2019 are assumed to have the same load periods. For this analysis there are 274 time intervals considered over the whole life-time, see Figure 12. Each time interval consists in a full power period and a decay period. For components with different irradiation histories for which measurements were performed the appropriate operational history was regarded and the decay periods from the time of removal until the time of measurement are accounted for, e.g. some screw nuts of the flange of the conical tube containing the cold neutron source container.

These screw nuts were removed and the activities of corresponding chip samples were measured.

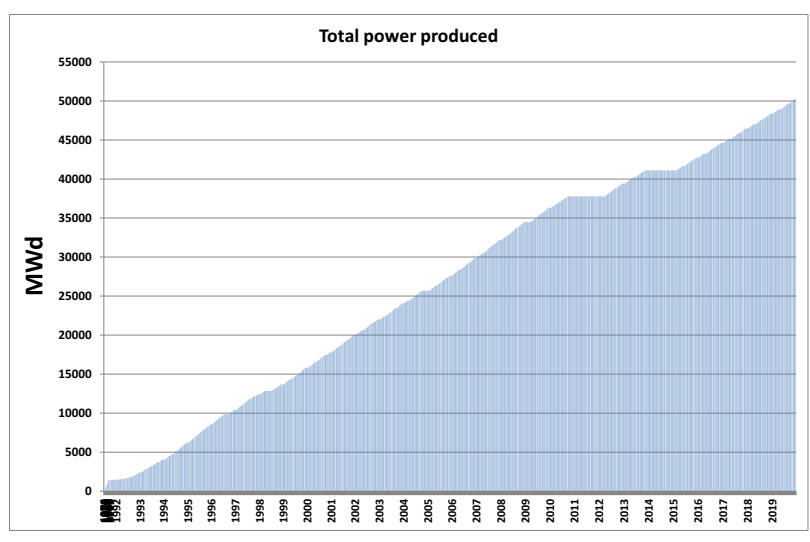

Figure 12: Total power production of the BER-II during operational lifetime including planned power production until 2019 (the year of 2016 is used for extrapolation).

\section{Results of the activation calculation and comparison with measurements at calibration points}

With the mesh wise neutron flux density distributions presented in the previous chapter, the activation calculations were performed with the burn-up and activation code FISPACT. For the determination of the activity distribution of important nuclides in the activated structures outside the core and reflector for all PARTISN or MCNP6 meshes containing irradiated material a FISPACT run was performed for the material of the mesh and the power history connected to the calculated flux spectrum. The power history of the BER-II is taken as shown in chapter 4 . The spatial and energetic flux shape remains the same during the whole irradiation period, only the flux amplitude varies with respect to the power produced in each irradiation interval. Effects of burn-up or moving of control rods are not accounted for.

As an example, the resulting Co-60 activity distribution in $\mathrm{Bq} / \mathrm{g}$ within the reactor geometry is presented in Figure 13 for the $\mathrm{x}, \mathrm{y}$-section at the height of the seven irradiation tubes. The values are given for the planned final shutdown time point. The complete set of $3 \mathrm{D}$ specific activity distributions are stored in a special data file in so called silo structure [9] which allow to show activity distributions for distinct $2 \mathrm{D}$ slices in $\mathrm{x}-\mathrm{y}$ or z-direction. With the graphical software VISIT [10] visualizations of activity distributions or single values are possible. 
The typical permitted limits for the most important nuclides in decommissioning are presented in Table 1 below [11]. The figure shows that the activation is strongly influenced by the neutron streaming through the beam tubes. The lower limit of the colour bar defines the unrestricted release value for the Co-60 activity. For the verification of the activation calculation, some measurements of components were provided by HZB. These measurements were performed at the irradiation channel inside the core and at the screw nuts on the flange of the conical irradiation tube, see Figure 14. The nuts were in the reactor from 1991 until week 40 of 2011. To account for spectral changes due to the adjacent steel bolts, the back flange is modelled with two bolts next to the observation point. The screw nuts were measured
Nov $23^{\text {rd }} 2015$. Another calibration point was an AlMg3 sample from the in-core irradiation channel. The results are presented in Table 2, and are in sufficient agreement with the measurement as a first estimate, even though the first calibration point (front flange) is somewhat underestimated. However, due to the fact that rod movement was not considered, and the height of the screw nuts on the front flange practically coincided with the lower tip of the control rod facing the cold neutron source, the deviations could be explained. More accurate values could be achieved if the realistic burnup distribution would be taken into account.

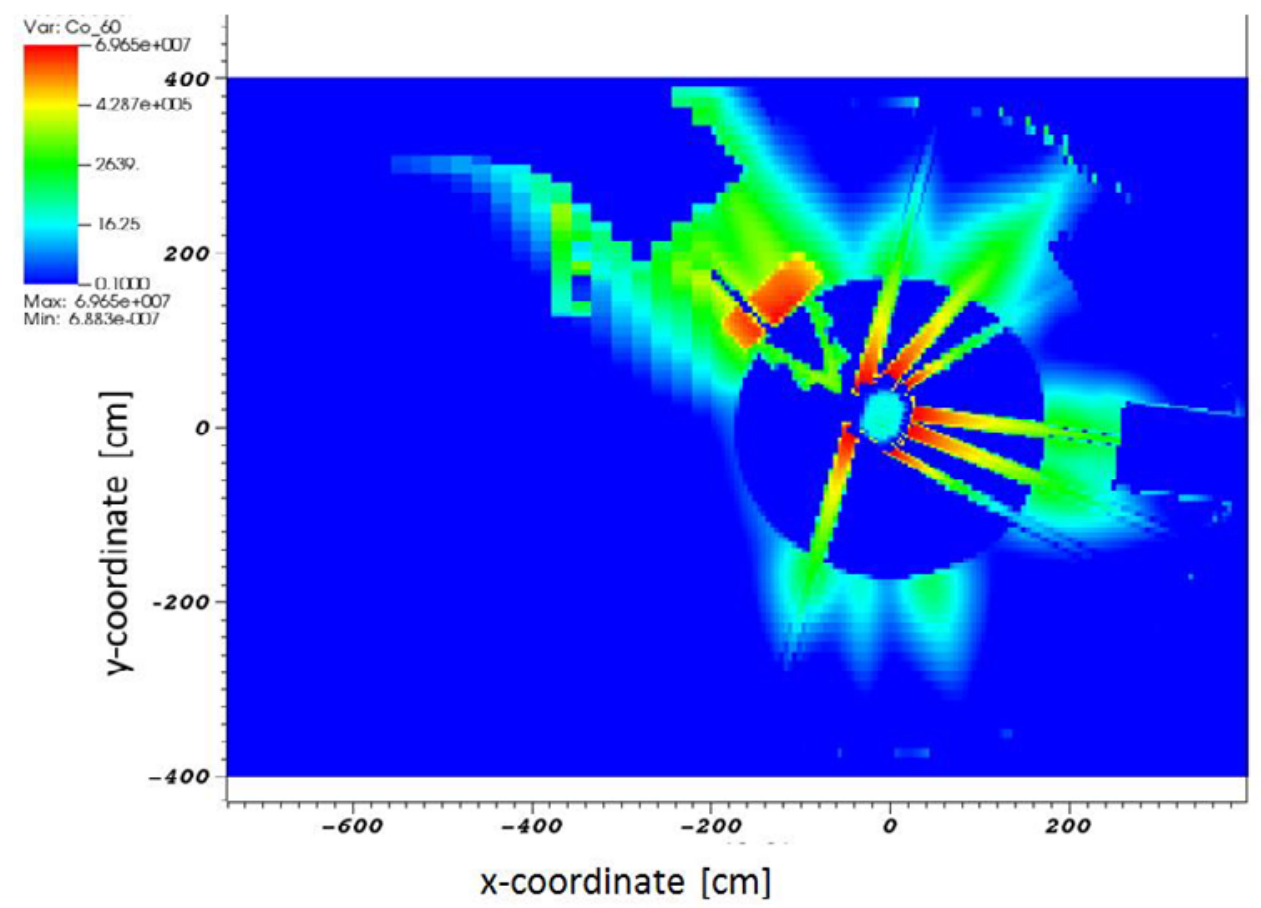

Figure 13: Distribution of Co-60 in Bq/g per gram of material mixture within a cell, $\mathrm{x}, \mathrm{y}$-section of the plane with 7 irradiation tubes at the end of operation

Table 1: Unrestricted release limits for different isotopes from the "Strahlenschutzverordnung"(German Radiation Protection Ordinance) [11]

\begin{tabular}{|l|c|c|c|}
\hline Isotope & Unrestricted & Restricted & Unit \\
\hline Co-60 & $1 \mathrm{E}-01$ & $6 \mathrm{E}-01$ & $\mathrm{~Bq} / \mathrm{g}$ \\
\hline Fe-55 & $2 \mathrm{E}+02$ & $1 \mathrm{E}+04$ & $\mathrm{~Bq} / \mathrm{g}$ \\
\hline $\mathrm{Eu}-152$ & $2 \mathrm{E}-01$ & $1 \mathrm{E}+01$ & $\mathrm{~Bq} / \mathrm{g}$ \\
\hline $\mathrm{H}-3$ & $1 \mathrm{E}+03$ & $6 \mathrm{E}+04$ & $\mathrm{~Bq} / \mathrm{g}$ \\
\hline $\mathrm{C}-14$ & $8 \mathrm{E}+01$ & $4 \mathrm{E}+03$ & $\mathrm{~Bq} / \mathrm{g}$ \\
\hline
\end{tabular}

Table 2: Comparison of the specific Co-60 activity, measured and calculated [2]

\begin{tabular}{|c|c|c|c|}
\hline Component & Position & Measured $[\mathrm{Bq} / \mathrm{g}]$ & Calculated $[\mathrm{Bq} / \mathrm{g}]$ \\
\hline Screw nut (stainless steel) & front flange & $5.84 \mathrm{E}+07$ & $3.81 \mathrm{E}+07$ \\
\hline Screw nut (stainless steel) & back flange & $9.9 \mathrm{E}+06$ & $1.12 \mathrm{E}+07$ \\
\hline Irradiation channel $(\mathrm{AlMg} 3)$ & inside the core & $2.4 \mathrm{E}+06$ & $4.12 \mathrm{E}+06$ \\
\hline
\end{tabular}




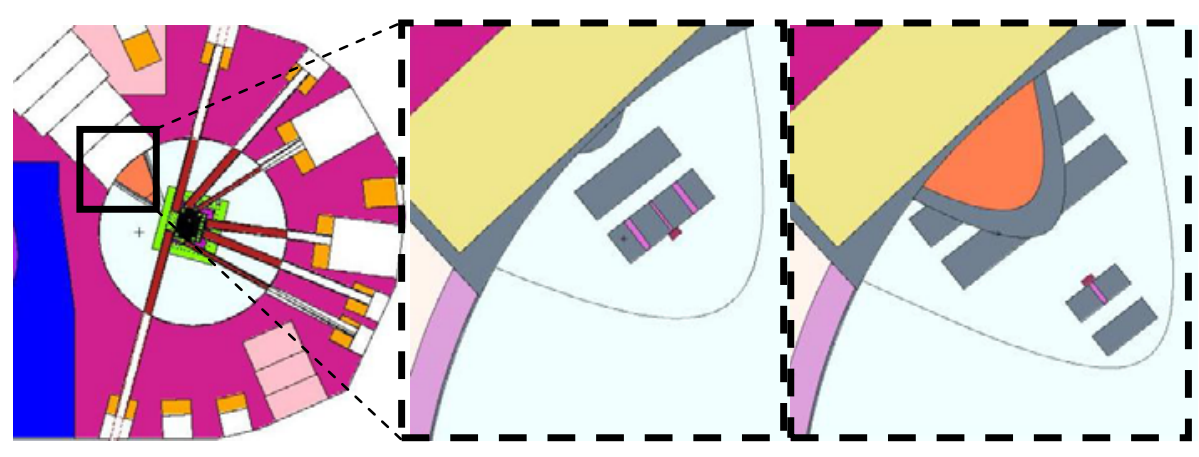

Figure 14: Location of calibration points for the activation analysis, measured values provided BER-2 operational staff

\section{Conclusion}

In this paper, a procedure for an activation calculation of the pool structure of the BER-II research reactor including the concrete shielding is presented. With the combination of the options offered by MCNP6 and PARTISN, an effective method to compute the neutron flux for a reactor geometry model with 2,790,000 cells could be achieved. The fact that for calculations with PARTISN some extra effort to generate the XS is needed is more than compensated by the fact that for all volumes of the model, neutron fluxes are produced that can be subsequently used for the activation calculation. With the power history provided together with the material compositions, an activation map was created for the whole structure, even for the most remote parts. The activity can be calculated for all nuclides of the FISPACT library. Dependent from material and irradiation history, however, only a limited number of nuclides must be regarded to reduce the size of activation data base.

The results for the activation at calibration points give an example that the use of detailed calculation methods allows reliable estimation of the activity of relevant nuclides, here Co-60. Especially the mean and the maximum activity can be determined. For a more detailed analysis, it is desirable to provide some more calibration points and realistic material specifications including impurities where the results of the activation can be validated, especially for more remote regions of the concrete structures.

\section{References}

1. H. Buchholz, C. O. Fischer, K. Waßerroth \& INTERATOM, „Sicherheitsbericht für den Reaktor BER-II" (engl.: Safety report for the BER-II reactor), (June 1972).
2. D.B. Pelowitz (Ed.), "MCNP6 ${ }^{\mathrm{TM}}$ User's Manual Version 1.0,” LA-CP-13-00634, Rev. 0 (2013).

3. R. E. Alcouffe, R. S. Baker, J. A. Dahl, S. A. Turner, R. C. Ward: "PARTISN: A time dependent, Parallel Neutral Particle Transport Code System”, LA-UR08-07258, (November 2008).

4. R. E. Alcouffe, R. S. Baker, J. A. Dahl, S. A. Turner, R. C. Ward: "PARTISN: A time dependent, Parallel Neutral Particle Transport Code System", LA-UR-0807258, (November 2008).

5. SCALE: A Comprehensive Modelling and Simulation Suite for Nuclear Safety Analysis and Design," ORNL/TM-2005/39, Version 6.1 (2011).

6. M.B. Chadwick, et. Al. : "ENDF/B-VII.1: Nuclear Data for Science and Technology: Cross Sections, Covariances, Fission Product Yields and Decay Data", Nucl. Data Sheets 112(2011)2887.

7. W. W. Engle, Jr., "A USER MANUAL FOR ANISN, A One Dimensional Discrete Ordinates Transport Code with Anisotropic Scattering", K1693, ORNL, (March 1967).

8. R. A. Forest: "FISPACT-2007: User manual", UKAEA FUS 534, (March 2007).

9. Silo Users Guide, Version 4.10, LLNL-SM-654357

10. VISIT Users Manual, Version 1.5: UCRL-SM220449, October 2005.

11. Verordnung über den Schutz vor Schäden durch ionisierende Strahlen \$29 Anhang 3 (engl.: German Radiation Protection Ordinance $\$ 28$ appendix 3), (Stand 11.12.2014). 